\title{
Characterisation of DOG-1 Expression in Salivary Gland Tumours and Comparison with Myoepithelial Markers
}

\author{
Syed A. Khurram ${ }^{1}$ (D) Paul M. Speight ${ }^{1}$
}

Received: 31 January 2018 / Accepted: 13 April 2018 / Published online: 18 April 2018

(c) The Author(s) 2018

\begin{abstract}
DOG1 is an established diagnostic marker for gastrointestinal stromal tumours (GIST), but has been reported in salivary gland tumours (SGT) as an acinar and intercalated duct marker. However, its specificity and distribution is not well established. The aim of this study was to evaluate the diagnostic utility of DOG-1 expression in SGT in addition to comparing it with myoepithelial markers. Normal salivary tissue and SGT $(n=184)$ were examined for expression of DOG1 and a range of myoepithelial markers. SGT included: acinic cell carcinoma (ACC, $n=15)$, secretory carcinoma $(S C, n=9)$, pleomorphic adenoma (PA, $n=49)$, carcinoma ex-PA (Ca ex-PA, $n=11)$, adenoid cystic carcinoma (AdCC, $n=20$ ), polymorphous adenocarcinoma (PAC, $n=6)$, myoepithelioma $(n=6)$, myoepithelial carcinoma $(M C, n=2)$, basal cell adenoma $(B C A, n=14)$, canalicular adenoma (CA, $n=19)$, mucoepidermoid carcinoma (MEC, $n=11)$, oncocytoma $(n=2)$, adenocarcinoma NOS (AdNOS, $n=4)$, basal cell adenocarcinoma (BCAC, $n=2)$, salivary duct carcinoma (SDC, $n=3$ ) and papillary cystadenocarcinoma (PCAC, $n=1)$. Normal acini and ACC (14/15) showed strong luminal DOG1 staining; SC were largely negative with only focal expression in 3/9 cases. Luminal staining was seen in PA (14/49), PAC (4/6), Ca ex-PA (4/11) and AdCC (6/20). 8/11 MEC showed luminal and/or mucous cell staining. No staining was seen in myoepithelioma, MC, CA, adNOS and BCAC. BCA showed strong staining of myoepithelial cells in some cases (5/14). Variable myoepithelial DOG1 staining was seen in PA, Ca ex PA, BCA, SDC and PCAC which was not as consistent as myoepithelial markers such as calponin, p63 and $\alpha$ SMA. Absence of DOG1 can differentiate ACC from SC, but staining is variable in PA, PLGA and Ca ex-PA. Myoepithelial staining in some tumours but not in normal gland suggests a wider distribution in SGT than originally envisaged.
\end{abstract}

Keywords DOG- 1 Salivary gland tumours $\cdot$ Acinic cell carcinoma $\cdot$ Secretory carcinoma $\cdot$ Myoepithelial $\cdot$ Luminal

\section{Introduction}

Diagnosing salivary gland tumours can be challenging due to the heterogeneity of the cellular differentiation, morphogenesis and histological patterns. Many different tumour entities share similar histological patterns, which further complicates diagnosis.

In 2004, 'Discovered on GIST-1' (DOG1) was shown to be highly expressed in a high proportion of gastrointestinal stromal tumours (GISTs) [1-3]. Subsequently, a number of in vivo studies revealed DOG1 to be a calcium activated chloride channel expressed on secretory epithelium in mouse models $[4,5]$. More recently, DOG1 expression has been

Syed A. Khurram

s.a.khurram@sheffield.ac.uk

1 Unit of Oral and Maxillofacial Pathology, School of Clinical Dentistry, 19 Claremont Crescent, Sheffield S10 2TA, UK reported in salivary gland tumours [6-8], in particular, as a marker for acinic and intercalated duct cells. Some studies have suggested that the DOG1 protein may be essential for salivary gland secretion with a possible role in salivary gland tumourigenesis [5, 9]. However, its pattern of expression and specificity in a range of tumours has not been fully established. Strong staining is seen at the luminal aspect of acinar cells in normal glands, and luminal staining has been shown in the acini in ACC [10], and in small ductal structures in PAC and epithelial myoepithelial carcinoma (EMC) [6]. Luminal and abluminal staining has been described in BCA and AdCC [6, 11]. Our clinical experience has shown expression by myoepithelial cells in some instances, a finding not reported to date.

The aim of this study was to study the expression pattern, specificity and diagnostic potential of DOG-1 in salivary gland tumours. 


\section{Methods}

Normal parotid and submandibular gland tissue and SGT $(n=184)$ were examined for expression of DOG1 and a range of myoepithelial and cytokeratin markers using immunohistochemistry (IHC) on cases retrieved from the department archive. These included acinic cell carcinoma (ACC, $n=15$ ), secretory carcinoma ( $S C, n=9$ ), pleomorphic adenoma (PA, $n=49)$, carcinoma ex-PA (Ca ex-PA, $n=11)$, adenoid cystic carcinoma (AdCC, $n=20$ ), polymorphous adenocarcinoma (PAC, $n=6)$, myoepithelioma $(n=6)$, myoepithelial carcinoma ( $\mathrm{MC}, \mathrm{n}=2)$, basal cell adenoma (BCA, $n=14)$, canalicular adenoma (CA, $n=19)$, mucoepidermoid carcinoma (MEC, $n=11)$, oncocytoma $(n=2)$, adenocarcinoma NOS (AdNOS, $n=4$ ), basal cell adenocarcinoma (BCAC, $n=2$ ), salivary duct carcinoma ( $S D C, n=3$ ) and a papillary cystadenocarcinoma $(\mathrm{PCAC}, \mathrm{n}=1)$.

The diagnosis of the cases was confirmed by $\mathrm{H} \& \mathrm{E}$ staining and examination under the light microscope. Tumours were classified according to WHO 2017 guidelines [12] and current literature. FISH analysis for the ETV6 rearrangement was used as a gold standard for the diagnosis of all included SC.

\section{Immunohistochemistry}

IHC for DOG1 was performed on the entire cohort. For comparison a range of other 'myoepithelial markers' were also studied in a proportion of tumours including S100, $\alpha$ SMA, p63, calponin and CK14 as previously described [8]. Multiple pilot assays were undertaken to determine the optimum dilution and conditions (Table 1).

$4 \mu$ thick sections from formalin-fixed, paraffin embedded tissue blocks were used for IHC staining. Sections were deparaffinised in xylene followed by incubation in ethanol for $5 \mathrm{~min}$ each. Endogenous peroxidase was blocked by incubation in 3\% methanolic $\mathrm{H}_{2} \mathrm{O}_{2}$ blocking solution for $20 \mathrm{~min}$ followed by a wash in phosphate buffered saline (PBS). Antigen retrieval was carried out by placing the slides in a heat-resistant plastic container filled with citrate or EDTA buffer solution in a microwave for $10 \mathrm{~min}$ on high power. The slides were left to cool for 2 min, placed in PBS to avoid dehydration and blocked with $100 \%$ normal serum for $30 \mathrm{~min}$ at room temperature (RT). Serum was removed followed by addition of the primary antibody overnight at $4{ }^{\circ} \mathrm{C}$ in a humidified chamber. Omission of primary antibody served as the negative control.

After overnight incubation, unbound primary antibody was removed and the slides washed twice for $5 \mathrm{~min}$ with PBS. The secondary antibody and ABC solution were prepared according to the manufacturer's instruction (Vectastain Elite kits, Vector Laboratories, Burlingame USA). Sections were covered with secondary antibody for $30 \mathrm{~min}$ followed by two washes in PBS and addition of avidin biotin complex (ABC) solution for $30 \mathrm{~min}$ at RT. After two further washes in PBS 3,3'-diaminobenzidine (DAB, Vector laboratories) was applied to the sections for 5-8 $\mathrm{min}$ and the colouring reaction stopped using distilled water. Sections were counterstained with Mayer's haematoxylin, mounted in DPX mounting media and left to dry at RT.

IHC staining was assessed subjectively under standard light microscopy, taking into account the pattern and localisation of the staining. Stained sections were photographed using a digital imaging system $\left(\operatorname{cell}^{\wedge} \mathrm{D}\right)$ and a digital camera attached to a light microscope (Olympus, UK). As previously described, myoepithelial staining was considered positive in the correct morphologic context to ensure exclusion of stromal cells [8].

\section{Results}

\section{DOG-1}

Strong apical/luminal DOG1 staining was seen in normal acini (10/10) (Fig. 1a), although occasional cells demonstrated lateral and basal expression. Staining was stronger in serous acini compared to mucous and focally intercalated ducts showed positive luminal reactivity. A similar staining pattern was seen in ACC, with widespread luminal DOG1 staining in 14 of the 15 cases (Fig. 1b). SC however were largely negative (Fig. 1c) with only weak focal luminal staining in three cases with a microcystic architecture (3/9) (Fig. 1d). SC with a papillary cystic architecture or clear cell change were negative. Variable luminal
Table 1 Details of primary antibodies used in the study

\begin{tabular}{lllll}
\hline Antibody & Clonality & Dilution & Retrieval & Supplier \\
\hline DOG 1 & Mouse monoclonal & $1: 250$ & EDTA & Dako®, Cambridgeshire, UK \\
S100 & Rabbit polyclonal & $1: 2,000$ & EDTA & Dako®, Cambridgeshire, UK \\
SMA & Mouse monoclonal & $1: 75$ & Citrate & Dako®, Cambridgeshire, UK \\
P63 & Mouse monoclonal & $1: 25$ & EDTA & Dako®, Cambridgeshire, UK \\
CK 14 & Mouse monoclonal & $1: 20$ & Citrate & Abcam ${ }^{\circledR}$, Cambridge, UK \\
Calponin & Rabbit monoclonal & $1: 100$ & Citrate & EP798Y, Abcam ${ }^{\circledR}$, Cambridge, UK \\
\hline
\end{tabular}




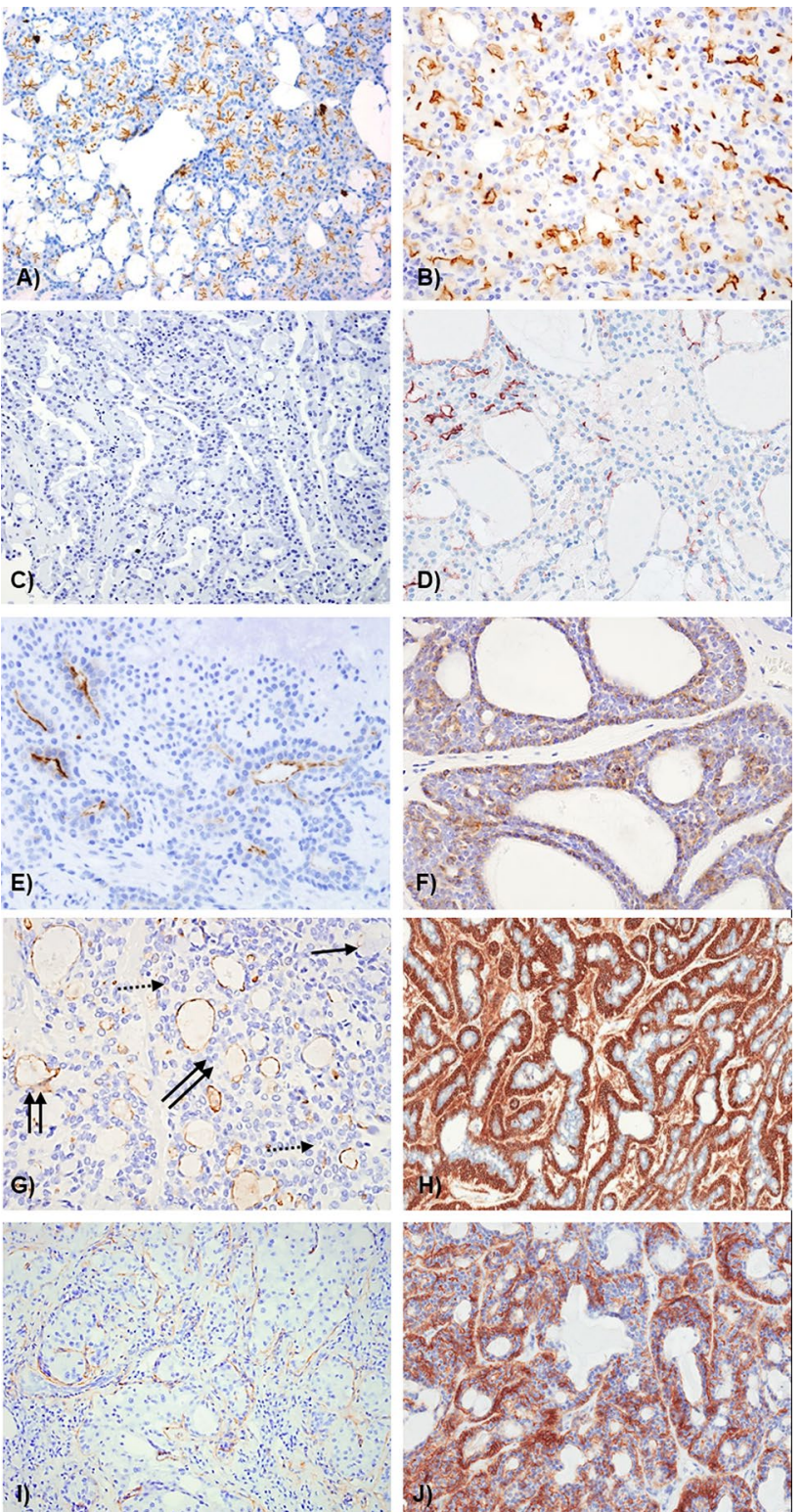

Fig. 1 Representative photomicrographs showing DOG-1 staining pattern in a normal gland; $\mathbf{b}$ acinic cell CA; $\mathbf{c}$ secretory carcinomanegative; $\mathbf{d}$ secretory carcinoma - focal positive, e pleomorphic adenoma; $\mathbf{f}$ adenoid cystic CA; $\mathbf{g}$ mucoepidermoid carcinoma; $\mathbf{h}$ basal cell adenoma; $\mathbf{i}$ carcinoma in pleomorphic adenoma; $\mathbf{j}$ papillary cystadenocarcinoma. g Solid arrow-mucous cells, dotted arrow-intermediate cells, double arrow-luminal spaces with DOG1 positivity

staining was seen in PA (14/49) (Fig. 1d), PAC (4/6 - not shown), Ca ex-PA (4/11) (Fig. 1i), AdCC (6/20) (Fig. 1e). MEC showed luminal and/or mucous cell staining in 8/11 cases (Fig. 1f). BCA showed strong staining of myoepithelial cells in 5/14 cases (Fig. 1h), and some myoepithelial staining was also seen in PA, Ca ex PA, BCA, SDC, AdCC and PCAC (Fig. 1; Table 2). No staining was seen in myoepitheliomas (0/6), MC (0/2), CA (0/19), AdNOS $(0 / 4)$ and BCAC (0/2).
Myoepithelial DOG-1 staining was compared with a range of existing markers including $\alpha$ SMA, calponin, p63, S100 and CK14.

\section{a-Smooth Muscle Actin (aSMA)}

Widespread $\alpha$ SMA staining was seen in myoepithelial cells surrounding the acini in normal salivary glands. The majority of the ACC and SC were negative for $\alpha \mathrm{SMA}$ with focal staining seen in only $4 / 14$ and 3/9 of cases. More consistent myoepithelial staining was seen in PA, Ca ex PA and myoepithelioma whereas PAC was negative.

Strong $\alpha$ SMA staining was also seen in abluminal cells of both tubular and cribriform AdCC (17/20 cases) consistent with myoepithelial cells. The three negative cases included two solid and one tubular AdCC.

Almost all cases of PAC were $\alpha$ SMA negative (not shown) whereas all basal cell adenomas demonstrated strong $\alpha$ SMA staining in the abluminal, myoepithelial cells. However, areas lacking $\boldsymbol{\alpha}$ SMA expression were also observed.

\section{Calponin}

ACCs and SC did not stain for calponin. Staining was seen in most cases of pleomorphic adenoma (44/47; 93.6\%) (Fig. 2a). Staining was frequently observed in abluminal and spindled myoepithelial cells whereas plasmacytoid cells were always negative. Similar to PA, 90\% (9/10) of Ca ex-PA showed Calponin staining in abluminal cells in addition to scattered stromal cells (Fig. 2b). Calponin staining was seen in myoepithelial cells in $66.7 \%$ of myoepitheliomas (4/6) (Fig. 2c). Focal staining was seen in myoepithelial carcinomas whereas PAC were largely negative with only one case showing some focal staining (Fig. 2d).

Calponin staining was seen in 16/20 (80\%) AdCC with expression in myoepithelial cells in both cribriform (Fig. 2e) and tubular (Fig. 3f) variants whereas the three negative cases had solid and mixed patterns.

\section{CK14}

In normal salivary glands, CK 14 staining was seen in myoepithelial cells surrounding acini and ducts (Fig. 3a). Both ACC and SC were largely negative for CK14; however 4/16 ACC showed focal CK14 staining (Fig. 3b) with diffuse staining seen in one SC (Fig. 3c).

For PA, 89.6\% (43/48) of the cases were CK14 positive with staining of both ductal and myoepithelial cells. However, staining was weak or absent in plasmacytoid cells, and cells in myxochondroid areas (Fig. 3d). CK 14 was diffusely positive in $90.9 \%$ of Ca-ex-PA (10/11) with strong staining in myoepithelial and abluminal cells throughout the tumours (Fig. 3e). 
Table 2 Summary of DOG1 staining in salivary gland neoplasms

\begin{tabular}{lrll}
\hline Site & Cases & +ve & Pattern \\
\hline Normal gland & 10 & $10 / 10$ & Acini \& ducts-luminal \\
Acinic cell carcinoma & 15 & $14 / 15$ & Diffuse luminal in acini and small ducts \\
Secretory carcinoma & 9 & $3 / 9$ & Negative or weak/focal luminal in microcystic areas \\
Pleomorphic adenoma & 49 & $14 / 49$ & Focal luminal or myoepithelial $(5 / 14)$ \\
Ca ex PA & 11 & $4 / 11$ & Luminal and/or myoepithelial cells $(2 / 4)$ \\
Myoepithelioma & 6 & $0 / 6$ & N/A \\
Myoepithelial carcinoma & 2 & $0 / 2$ & N/A \\
Adenoid cystic carcinoma & 20 & $6 / 20$ & Weak abluminal + luminal \\
Polymorphous adenocarcinoma & 6 & $4 / 6$ & Focal luminal \\
Basal cell adenoma & 14 & $5 / 14$ & Luminal or abluminal/myoepithelial—variable (5/5) \\
Canalicular adenoma & 19 & $0 / 19$ & N/A \\
Mucoepidermoid carcinoma & 11 & $8 / 11$ & Luminal + mucous cell brush borders \\
Oncocytoma & 2 & $0 / 2$ & N/A \\
Adenocarcinoma NOS & 4 & $0 / 4$ & N/A \\
Basal cell adenocarcinoma & 2 & $0 / 2$ & N/A \\
Salivary duct carcinoma & 3 & $1 / 3$ & Myoepithelial cells (1/1) \\
Papillary cystadenocarcinoma & 1 & $1 / 1$ & Abluminal/myoepithelial cells (1/1) \\
Total & 184 & 70 & \\
\hline
\end{tabular}

For each tumour type the total number of positive cases is given in relation to the total number of the cases
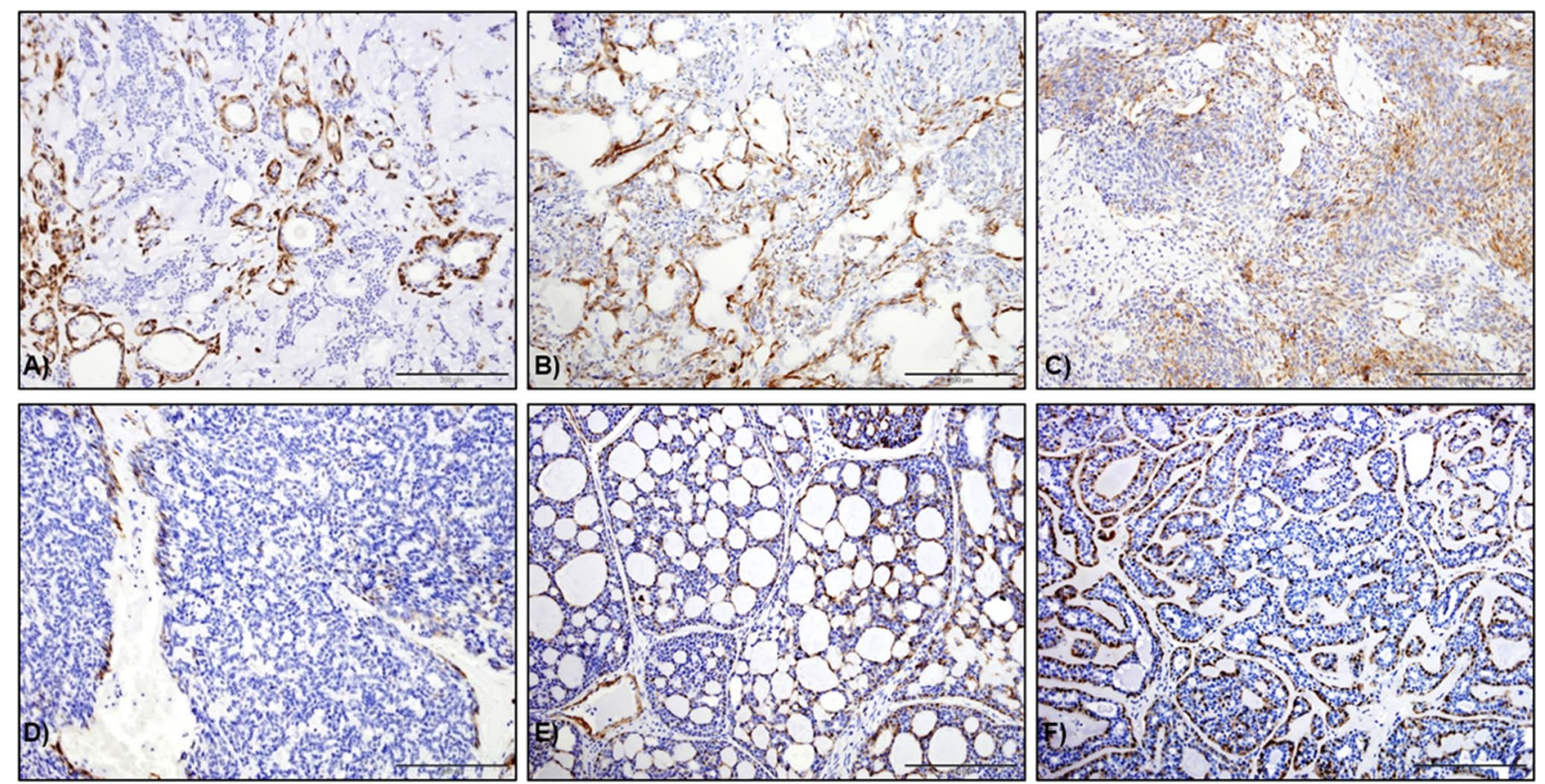

Fig. 2 Calponin staining in a pleomorphic adenoma, b Ca ex-pleomorphic adenoma, c myoepithelioma and $\mathbf{d}$ PAC. Staining was predominantly seen in myoepithelial cells surrounding the ductal areas in $(\mathbf{a}, \mathbf{b})$. In $\mathbf{c}$, scattered staining in spindle cells was seen throughout.

In myoepithelioma, CK14 was variably positive in myoepithelial cells in $5 / 6$ of the cases (83.3\%), mainly in cells with
PAC were negative except with one case showing focal staining. d Calponin staining highlighting the abluminal/myoepithelial cells Cribriform AdCC and $\mathbf{e}$ tubular AdCC (original magnification $\times 20$ )

spindled morphology (Fig. 3f). Both cases of myoepithelial carcinoma showed focal staining of the tumour cells (Fig. 3g). 

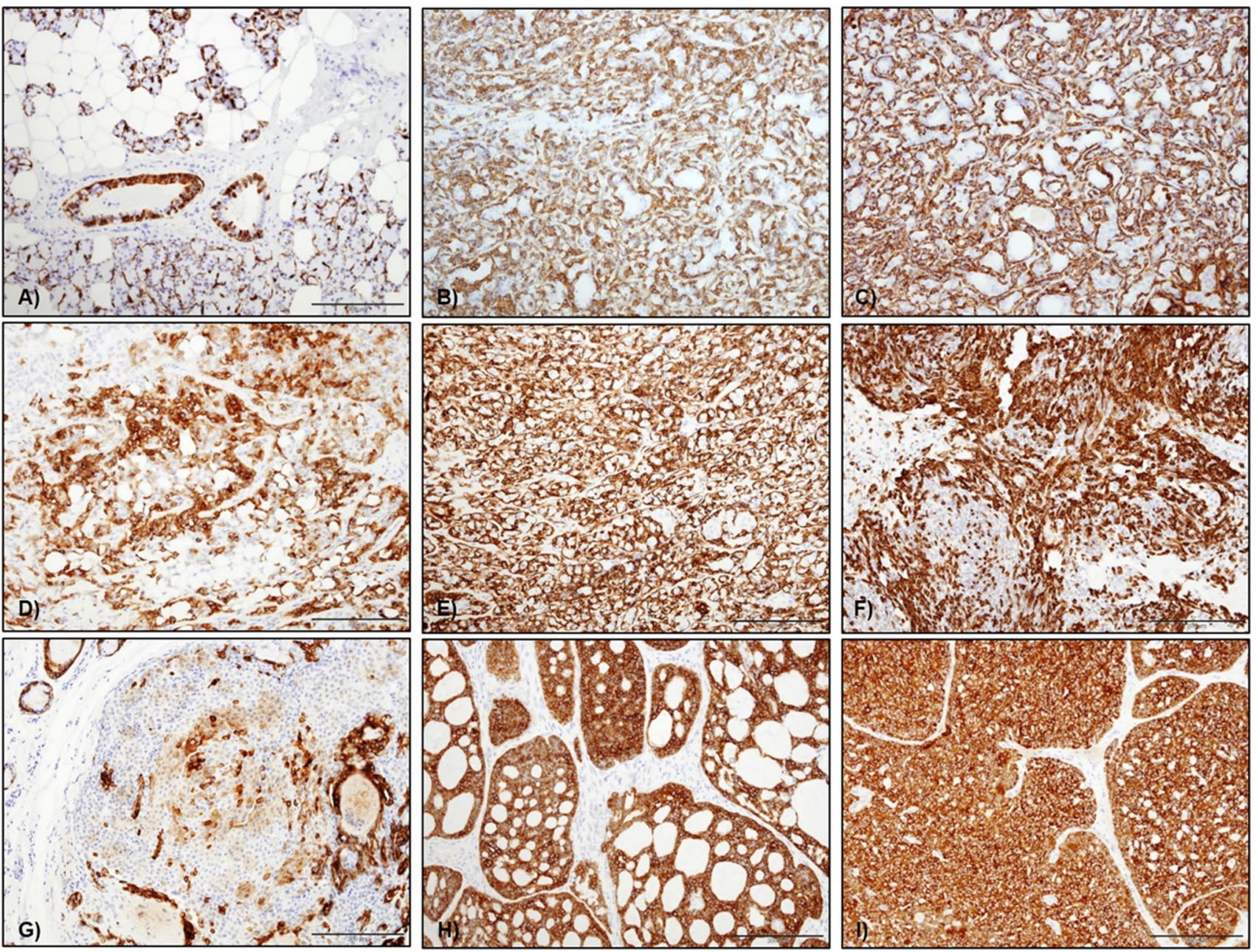

Fig. 3 CK14 staining in salivary gland tumours a in normal tissue CK14 staining was mainly seen as a cytoplasmic staining of myoepithelial cells surrounding acini and in some basal cell in ducts, b CK14 in ACC was variable with one case showing diffuse abluminal staining, c CK14 in one SC with diffuse cytoplasmic staining of abluminal cells, d CK14 staining in PA was predominantly seen in the cytoplasm of most tumour cells, but plasmacytoid cells were negative, e CK14 expression in CA ex-PA was mainly seen in the cytoplasm of the abluminal type cells, f CK14 staining in myoepithelioma was variably positive in the cytoplasm of the neoplastic myoepithelial cells, mainly spindle cells, g CK14 staining in MC was focal with cytoplasmic staining of scattered tumour cells, i CK14 staining in AdCC (cribriform variant) and $\mathbf{j}$ PAC-diffuse staining was seen throughout the tumour (original magnification $\times 20$ )
CK 14 staining in AdCC was observed in 13 out of 14 examined cases with strong diffuse staining in both luminal and abluminal cells (Fig. $3 \mathrm{~h}$ ). Variable reactivity of the tumour cells was seen in the tubular variant which also showed weaker staining intensity compared to tumours with a cribriform pattern. The only negative AdCC case had a solid architecture.

All cases of PAC showed diffuse CK14 staining. The staining was strong and diffuse throughout tumour cells (Fig. 3i). The variable expression profile of CK14 between different tumours indicates that it is not a reliable or specific myoepithelial marker.

\section{S100}

Diffuse S100 staining was seen in myoepithelial cells in normal glands. Some ACC showed weak focal staining in acini, however most were negative. Cases with solid and papillary cystic patterns were completely negative for S100.

All cases of SC (9/9) were S100 positive and showed strong and diffuse staining of nuclei and cytoplasm of tumour cells (Fig. 4a). All PA (44/44; 100\%) showed diffuse S100 staining including in spindle and plasmacytoid myoepithelial cells as well as cells within myxoid tissue (Fig. 4b). All cases of Ca-ex-PA (11/11) showed similar reactivity (Fig. 4c). 

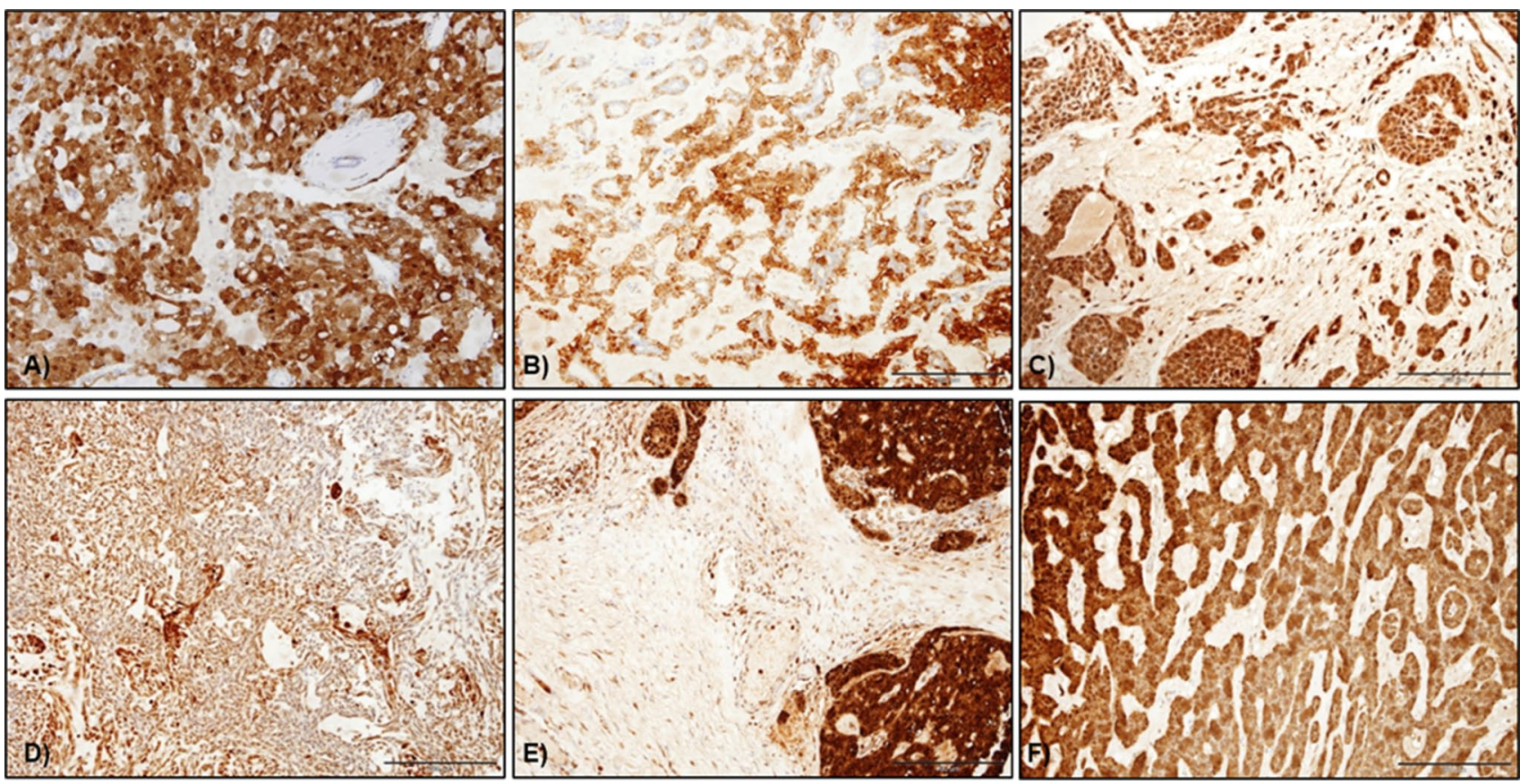

Fig. 4 S100 staining in salivary gland tumours. a Nuclear and cytoplasmic staining in myoepithelial cells in PA whereas luminal cells were largely negative, b S100 expression in Ca ex-PA with diffuse staining in the cytoplasm of luminal, abluminal and scattered stromal

There was strong and diffuse S100 reactivity in all myoepitheliomas (6/6) and myoepithelial carcinomas (2/2) including spindled and plasmacytoid cells (Fig. 4d, e). All examined cases of AdCC (14/14) were positive for S100. Staining was observed mainly in the luminal cells of the ducts or cystic structures in the tubular and cribriform cases with some showing both luminal and abluminal staining. Diffuse staining was seen in the solid variant, but with less intensity. All five cases of PAC (100\%) were positive for S100, with all the neoplastic cells showing diffuse strong to moderate cytoplasmic staining (Fig. 4f).

\section{p63}

In ACC, 14/16 (87.5\%) of the examined cases were p63 negative, with only two cases showing focal staining. Staining in SC was also variable with only $3 / 9$ cases showing p63 positivity (not shown).

44/49 cases of PA (89.8\%) showed p63 staining in abluminal and myoepithelial cells. Ca-ex-pleomorphic adenoma showed a similar staining distribution, pattern and intensity in $90.9 \%(10 / 11)$ of the cases. $100 \%$ of myoepitheliomas (6/6) showed strong nuclear staining in spindle and plasmacytoid cells. However, only one case of myoepithelial carcinoma (1/2) was positive, with focal areas of nuclear staining of the tumour cells. cells, c myoepithelioma showing diffuse cytoplasmic S100 staining in the neoplastic spindle cells, d S100 staining in MC with strong cytoplasmic staining in the plasmacytoid cells, e PAC showed diffuse staining in almost all the tumour cells (original magnification $\times 20$ )

In AdCC, 9/12 (75\%) of the cases were p63 positive mainly in the abluminal cells, whereas luminal cells in ductal and tubular areas were negative. The negative cases showed a mostly solid pattern. All cases of PAC and BCA showed p63 staining in abluminal cells with stronger and more widespread staining seen in BCA.

Comparison with other myoepithelial markers showed that all cases with DOG-1 staining in myoepithelial cells were also positive for $\alpha$ SMA, calponin, CK14 and p63. In addition, only a limited number of PA, Ca ex PA and AdCC showed abluminal and/or myoepithelial DOG-1 positivity compared to other markers.

\section{Discussion}

\section{DOG-1 Expression}

DOG1 has been reported as a marker for differentiated acinic cells and intercalated duct cells [6], and is thought to be particularly useful for the diagnosis of ACC. In the current study, we examined a wide range of salivary neoplasms to determine the expression profile and distribution of DOG1 and report expression in myoepithelial cells for the first time.

ACC showed diffuse luminal DOG1 staining in 14/15 (93.3\%) of the examined cases in agreement with the literature and similar to the staining pattern seen in the acini 
of normal glands $[6,7,10,11,13-17]$. Staining of duct cells was patchy and weak but widespread luminal staining was evident in all tumours. The majority of SC lacked DOG1 staining, similar to previous reports [6-8, 15, 18], confirming the diagnostic usefulness of DOG-1 in differentiating between ACC and SC.

$28 \%$ of pleomorphic adenomas showed some DOG-1 staining with a predominantly apical/luminal pattern as previously reported $[6,17]$. However, staining in myoepithelial cells was seen in 5 cases, which is a novel finding. A similar pattern was seen in carcinoma ex PA with apical/ luminal staining in addition to myoepithelial staining in two cases whereas no staining was evident in myoepitheliomas or myoepithelial carcinomas.

Only two cases of AdCC showed weak focal reactivity for DOG-1. The first had a tubular pattern with DOG1 staining of the luminal aspect of the tubules, while the second showed a mixture of solid and cribriform patterns with occasional cells staining towards the periphery of the solid tumour islands. These are somewhat different to previous findings $[6,19]$ which reported consistent luminal staining within the cribriform areas. The reason for this difference is not entirely clear but lack of DOG1 staining in AdCC and difference between antibody clones has been reported by other groups [17].

Expression of DOG1 in PAC was only seen in two of five cases and showed only focal luminal expression similar to a previous report [6]. Somewhat similar to our findings, Montalli et al. reported cytoplasmic DOG1 staining in a 4/21 PACs in their cohort with cytoplasmic or occasionally apical staining [11].

Five cases of basal cell adenoma showed strong and diffuse staining for DOG1 in abluminal cells, which was similar to the pattern of $\alpha$ SMA and p63 staining, and was consistent with strong expression of DOG-1 on myoepithelial cells. Luminal staining was also seen focally in two cases. Montalli et al. suggested that staining was luminal in tubular and abluminal in non-tubular BCAs but we did not observe an obvious correlation between histological and staining patterns [20]. However, our BCA cohort was smaller including solid, tubular and non-tubular variants making it difficult to establish a relationship between morphology and staining.

MEC showed focal staining for DOG1 in 8 cases. In 3 this was weak luminal staining, and in the remainder there was weak or faint expression at the margins of mucous cells. This is somewhat similar to a previous study reporting weak staining in mucous and intermediate cells in MEC [19]. Canberk et al. studied FNAs from salivary tumours reporting DOG- 1 cytoplasmic staining in $14 \%$ of cases but did not describe the precise location of the staining [17]. Myoepithelial staining for DOG1 was also seen in one adenocarcinoma NOS and a papillary cyst adenocarcinoma.

\section{Expression of Myoepithelial Markers}

Calponin appeared to the most specific and sensitive myoepithelial marker followed by $\alpha$ SMA and p63. In some AdCC, PA and BCA, DOG-1 variable staining in myoepithelial cells was seen. ACC and SC were largely negative for myoepithelial markers similar to previous reports [7, 21-23]. S100 was very useful in differentiating between these two entities as strong diffuse $\mathrm{S} 100$ staining was seen in all SC but ACC were negative except for occasional focal and weak staining. This supports previous reports in the literature [7, 14, 24-27] and further confirms the diagnostic usefulness of S100 in SC [8].

$\alpha$ SMA was expressed in the majority of PA in abluminal and myoepithelial cells whereas plasmacytoid cells were negative $[28,29]$. Calponin staining was present in all analysed cases including plasmacytoid cells indicating higher sensitivity than $\alpha$ SMA [30]. Abluminal/myoepithelial staining for $\mathrm{S} 100$ and $\mathrm{p} 63$ was also seen in all cases and similar profile was exhibited by Ca ex-PA [26, 31, 32]. $\alpha$ SMA, calponin and p63 staining in AdCC was variable, but was mainly seen in myoepithelial cells surrounding tubular and cribriform structures [33, 34]. Almost all cases demonstrated diffuse luminal and abluminal staining for CK14, suggesting a lack of specificity. In PAC, staining for $\alpha$ SMA and calponin were largely negative, but diffuse CK14 and S100 staining was seen in most tumour cells $[35,36]$ whereas p63 staining was limited to abluminal cells [37].

\section{Conclusion}

Absence of luminal DOG-1 staining can differentiate ACC from SC, but variable staining is seen in PA, PLGA and $\mathrm{Ca}$ ex-PA. Myoepithelial staining in some tumours but not in normal gland is an interesting finding suggesting a wider distribution in SGT than originally envisaged. However, DOG-1 staining in myoepithelial cells appears inconsistent and not as reliable and sensitive as the existing markers, limiting its diagnostic utility.

\section{Compliance with Ethical Standards}

Conflict of interest No conflict of interest to disclose.

Ethical Approval All procedures performed in studies involving human participants were in accordance with the ethical standards of the institutional and/or national research committee and with the 1964 Helsinki declaration and its later amendments or comparable ethical standards. NRES Committee Yorkshire and Humber-Sheffield (South Sheffied REC)—Reference 05/Q2305/127. 
Open Access This article is distributed under the terms of the Creative Commons Attribution 4.0 International License (http://creativeco mmons.org/licenses/by/4.0/), which permits unrestricted use, distribution, and reproduction in any medium, provided you give appropriate credit to the original author(s) and the source, provide a link to the Creative Commons license, and indicate if changes were made.

\section{References}

1. Espinosa I, Lee CH, Kim MK, Rouse BT, Subramanian S, Montgomery K, Varma S, Corless CL, Heinrich MC, Smith KS, Wang Z, Rubin B, Nielsen TO, Seitz RS, Ross DT, West RB, Cleary ML, van de Rijn M. A novel monoclonal antibody against DOG1 is a sensitive and specific marker for gastrointestinal stromal tumors. Am J Surg Pathol. 2008;32(2):210-8.

2. Miettinen M, Wang ZF, Lasota J. DOG1 antibody in the differential diagnosis of gastrointestinal stromal tumors: a study of 1840 cases. Am J Surg Pathol. 2009;33(9):1401-8.

3. Wada T, Tanabe S, Ishido K, Higuchi K, Sasaki T, Katada C, Azuma M, Naruke A, Kim M, Koizumi W, Mikami T. DOG1 is useful for diagnosis of KIT-negative gastrointestinal stromal tumor of stomach. World J Gastroenterol. 2013;19(47):9133-6.

4. Simon S, Grabellus F, Ferrera L, Galietta L, Schwindenhammer B, Mühlenberg T, Taeger G, Eilers G, Treckmann J, Breitenbuecher F, Schuler M, Taguchi T, Fletcher JA, Bauer S. DOG1 regulates growth and IGFBP5 in gastrointestinal stromal tumors. Cancer Res. 2013;73(12):3661-70.

5. Yang YD, Cho H, Koo JY, Tak MH, Cho Y, Shim WS, Park SP, Lee J, Lee B, Kim BM, Raouf R, Shin YK, Oh U. TMEM16A confers receptor-activated calcium-dependent chloride conductance. Nature. 2008;455(7217):1210-5.

6. Chênevert J, Duvvuri U, Chiosea S, Dacic S, Cieply K, Kim J, Shiwarski D, Seethala RR. DOG1: a novel marker of salivary acinar and intercalated duct differentiation. Mod Pathol. 2012;25(7):919-29.

7. Urano M, Nagao T, Miyabe S, Ishibashi K, Higuchi K, Kuroda M. Characterization of mammary analogue secretory carcinoma of the salivary gland: discrimination from its mimics by the presence of the ETV6-NTRK3 translocation and novel surrogate markers. Hum Pathol. 2015;46(1):94-103.

8. Khurram SA, Sultan-Khan J, Atkey N, Speight PM. Cytogenetic and immunohistochemical characterisation of Mammary Analogue Secretory Carcinoma of Salivary glands. Oral Surg Oral Med Oral Pathol Oral Radiol. 2016;122(6):731-42.

9. Almaça J, Tian Y, Aldehni F, Ousingsawat J, Kongsuphol P, Rock JR, Harfe BD, Schreiber R, Kunzelmann K. TMEM16 proteins produce volume-regulated chloride currents that are reduced in mice lacking TMEM16A. J Biol Chem. 2009;284(42):28571-8.

10. Skálová A, Vanecek T, Majewska H, Laco J, Grossmann P, Simpson RH, Hauer L, Andrle P, Hosticka L, Branžovský J, Michal M. Mammary analogue secretory carcinoma of salivary glands with high-grade transformation: report of 3 cases with the ETV6NTRK 3 gene fusion and analysis of TP53, $\beta$-catenin, EGFR, and CCND1 genes. Am J Surg Pathol. 2014;38(1):23-33.

11. Montalli VA, Passador-Santos F, Martinez EF, Furuse C, Aguiar MC, Soares FA, Soares AB, Brown AL, de Araújo NS, de Araújo VC. Mammaglobin and DOG-1 expression in polymorphous lowgrade adenocarcinoma: an appraisal of its origin and morphology. J Oral Pathol Med. 2017;46(3):182-7.

12. El-Naggar AK, Chan JKC, Grandis JR, Takata T, Slootweg PJ, editors. WHO classification of head and neck tumours. Lyon: ARC Press; 2017.

13. Schmitt AC, Cohen C, Siddiqui MT. Expression of SOX10 in salivary gland oncocytic neoplasms: a review and a comparative analysis with other immunohistochemical markers. Acta Cytol. 2015;59(5):384-90.

14. Pinto A, Nosé V, Rojas C, Fan YS, Gomez-Fernandez C. Searching for mammary analogue [corrected] secretory carcinoma of salivary gland among its mimics. Mod Pathol. 2014;27(1):30-7.

15. Naous R, Zhang S, Valente A, Stemmer M, Khurana KK. Utility of immunohistochemistry and ETV6 (12p13) gene rearrangement in identifying secretory carcinoma of salivary gland among previously diagnosed cases of acinic cell carcinoma. Pathol Res Int. 2017;2017:1497023.

16. Said-Al-Naief N, Carlos R, Vance GH, Miller C, Edwards PC. Combined DOG1 and mammaglobin immunohistochemistry is comparable to ETV6-breakapart analysis for differentiating between papillary cystic variants of acinic cell carcinoma and mammary analogue secretory carcinoma. Int J Surg Pathol. 2017;25(2):127-40.

17. Canberk S, Onenerk M, Sayman E, Goret CC, Erkan M, Atasoy $\mathrm{T}$, Kilicoglu GZ. Is DOG1 really useful in the diagnosis of salivary gland acinic cell carcinoma?-a DOG1 (clone K9) analysis in fine needle aspiration cell blocks and the review of the literature. CytoJournal. 2015;12:18.

18. Stevens TM, Kovalovsky AO, Velosa C, Shi Q, Dai Q, Owen RP, Bell WC, Wei S, Althof PA, Sanmann JN, Sweeny L, Carroll WR, Siegal GP, Bullock MJ, Brandwein-Gensler M. Mammary analog secretory carcinoma, low-grade salivary duct carcinoma, and mimickers: a comparative study. Mod Pathol. 2015;28(8):1084-100.

19. Abd Raboh NM, Hakim SA. Diagnostic role of DOG1 and p63 immunohistochemistry in salivary gland carcinomas. Int J Clin Exp Pathol. 2015;8(8):9214-22.

20. Montalli VA, Martinez E, Tincani A, Martins A, Abreu Mdo C, Neves C, Costa AF, Araújo VC, Altemani A. Tubular variant of basal cell adenoma shares immunophenotypical features with normal intercalated ducts and is closely related to intercalated duct lesions of salivary gland. Histopathology. 2014;64(6):880-9.

21. Zhu S, Schuerch C, Hunt J. Review and updates of immunohistochemistry in selected salivary gland and head and neck tumors. Arch Pathol Lab Med. 2015;139(1):55-66.

22. Laco J, Švajdler M Jr, Andrejs J, Hrubala D, Hácová M, Vaněček T, Skálová A, Ryška A. Mammary analog secretory carcinoma of salivary glands: a report of 2 cases with expression of basal/myoepithelial markers (calponin, CD10 and p63 protein). Pathol Res Pract. 2013;209(3):167-72.

23. Bishop JA, Yonescu R, Batista D, Begum S, Eisele DW, Westra WH. Utility of mammaglobin immunohistochemistry as a proxy marker for the ETV6-NTRK3 translocation in the diagnosis of salivary mammary analogue secretory carcinoma. Hum Pathol. 2013;44(10):1982-8.

24. Sethi R, Kozin E, Remenschneider A, Meier J, VanderLaan P, Faquin W, Deschler D, Frankenthaler R. Mammary analogue secretory carcinoma: update on a new diagnosis of salivary gland malignancy. Laryngoscope. 2014;124(1):188-95.

25. Mariano FV, dos Santos HT, Azañero WD, da Cunha IW, Coutinho-Camilo CM, de Almeida OP, Kowalski LP, Altemani A. Mammary analogue secretory carcinoma of salivary glands is a lipid-rich tumour, and adipophilin can be valuable in its identification. Histopathology. 2013;63(4):558-67.

26. Luo W, Lindley SW, Lindley PH, Krempl GA, Seethala RR, Fung KM. Mammary analog secretory carcinoma of salivary gland with high-grade histology arising in hard palate, report of a case and review of literature. Int J Clin Exp Pathol. 2014;7(12):9008-22.

27. Shah AA, Wenig BM, LeGallo RD, Mills SE, Stelow EB. Morphology in conjunction with immunohistochemistry is sufficient 
for the diagnosis of mammary analogue secretory carcinoma. Head Neck Pathol. 2015;9(1):85-95.

28. Furuse C, Sousa SO, Nunes FD, Magalhães MH, Araújo VC. Myoepithelial cell markers in salivary gland neoplasms. Int J Surg Pathol. 2005;13(1):57-65.

29. Santos EP, Cavalcante DR, Melo AU, Pereira JC, Gomes MZ, Albuquerque RL Jr. Plasmacytoid myoepithelioma of minor salivary glands: report of case with emphasis in the immunohistochemical findings. Head Face Med. 2011;7:24.

30. Cavalcante RB, Lopes FF, Ferreira AS, Freitas RDA, de Souza LB. Immunohistochemical expression of vimentin, calponin and HHF-35 in salivary gland tumors. Braz Dent J. 2007;18(3):192-7.

31. Zhao J, Wang J, Yu C, Guo L, Wang K, Liang Z, Lou J. Prognostic factors affecting the clinical outcome of carcinoma ex pleomorphic adenoma in the major salivary gland. World J Surg Oncol. 2013;11(1):180.

32. Di Palma S, Lambros MB, Savage K, Jones C, Mackay A, Dexter T, Iravani M, Fenwick K, Ashworth A, Reis-Filho JS. Oncocytic change in pleomorphic adenoma: molecular evidence in support of an origin in neoplastic cells. J Clin Pathol. 2007;60(5):492-9.
33. Namboodiripad PC. A review: immunological markers for malignant salivary gland tumors. J Oral Biol Craniofac Res. 2014;4(2):127-34.

34. Simpson RH, Skálová A, Di Palma S, Leivo I. Recent advances in the diagnostic pathology of salivary carcinomas. Virchows Arch. 2014;465(4):371-84.

35. Araújo V, Sousa S, Jaeger M, Jaeger R, Loyola A, Crivelini M, Araújo N. Characterization of the cellular component of polymorphous low-grade adenocarcinoma by immunohistochemistry and electron microscopy. Oral Oncol. 1999;35(2):164-72.

36. Perez-Ordonez B, Linkov I, Huvos AG. Polymorphous lowgrade adenocarcinoma of minor salivary glands: a study of 17 cases with emphasis on cell differentiation. Histopathology. 1998;32(6):521-9.

37. Rooper L, Sharma R, Bishop JA. Polymorphous low grade adenocarcinoma has a consistent p63+/p40- immunophenotype that helps distinguish it from adenoid cystic carcinoma and cellular pleomorphic adenoma. Head Neck Pathol. 2015;9(1):79-84. 